\title{
Spectroscopic Investigation of Rare-Earth Doped Phosphate Glasses Containing Silver Nanoparticles
}

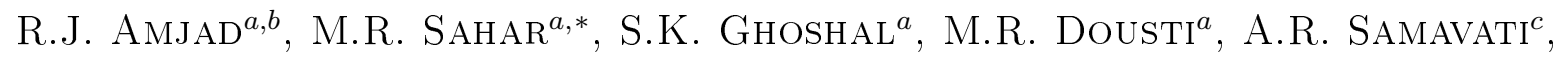 \\ S. RIAZ ${ }^{b}$ AND B.A. TAHIR ${ }^{a}$ \\ ${ }^{a}$ Advanced Optical Material Research Group, Faculty of Science, Universiti Teknologi Malaysia \\ 81310 Skudai, Johor, Malaysia \\ ${ }^{b}$ Centre for Solid State Physics, University of the Punjab, QAC, Lahore-54590, Pakistan \\ ${ }^{c}$ Ibn Sina Institute for Fundamental Science Studies, Universiti Teknologi Malaysia \\ 81310 Skudai, Johor, Malaysia
}

(Received March 13, 2012; revised version October 17, 2012; in final form January 21, 2013)

Phosphate glasses having compositions $(59.5-x) \mathrm{P}_{2} \mathrm{O}_{5}-40 \mathrm{MgO}-x \mathrm{AgCl}-0.5 \mathrm{Er}_{2} \mathrm{O}_{3}$, where $x=0,1.5 \mathrm{~mol} . \%$ is prepared using melt-quenching technique. Infrared, absorption and photoluminescence spectra of $\mathrm{Er}^{3+}-\mathrm{doped}$ magnesium phosphate glasses have been reported. The amorphous nature of the host glass is confirmed by X-ray diffraction technique. Transmission electron microscope image confirms the existence of silver nanoparticles inside the glass matrix. The localized surface plasmon resonance band of silver is found to be located around $\approx 528 \mathrm{~nm}$ for the $\mathrm{Er}^{3+}$ free sample. A frequency upconversion process from infrared to visible is observed on excitation with $797 \mathrm{~nm}$ radiation. Furthermore, an enhancement in the emission at $540 \mathrm{~nm}$ and $632 \mathrm{~nm}$ is found due to the local field effect of silver nanoparticles. Our findings may contribute towards the development of solid state laser and sensors.

DOI: $10.12693 /$ APhysPolA.123.746

PACS: 78.30.Ly, 78.55.-m, 78.66.Jg

\section{Introduction}

Rare-earth doped glasses containing metallic nanoparticles (NPs) are attractive because the presence of NPs can enhance the upconversion (UC) luminescence [1-3] and the nonlinear properties [4] suitable for optical device applications. The resonance of the surface plasmon frequency of the NPs with the frequency of excitation beam and/or the materials luminescence frequency makes the emission enhanced by many folds [5]. Amongst many other glasses the $\mathrm{P}_{2} \mathrm{O}_{5}$ based glasses find widespread applications in optical data transmission, detection and laser technologies [6]. They present superior properties that include high transparency, low melting point, high thermal stability, high gain density, high solubility for rare-earth ions and low dispersion [7]. Current research is primarily focused on the enhancement of UC luminescence and quantum efficiency minimizing the concentration quenching and multiphonon relaxation. The local field effect around the rare-earth ions plays a major role and thereby it is believed to enhance the UC luminescence and needs more careful theoretical and experimental study. Therefore, in the present study $\mathrm{Er}^{3+}$ doped phosphate glasses with and without silver NPs are prepared using the conventional melt-quenching method and

*corresponding author; e-mail: mrahim057@gmail.com their UV-Vis absorption and UC luminescence are performed for the optical characterization. The role of the silver NPs in enhancing the red and green emissions of $\mathrm{Er}^{3+}$ ions are investigated in detail and a mechanism is proposed to explain this phenomenon.

\section{Experimental}

The following compositions are tried: glass E: 59.5 $\mathrm{P}_{2} \mathrm{O}_{5}-40 \mathrm{MgO}-0.5 \mathrm{Er}_{2} \mathrm{O}_{3}$; glass AE: $58 \mathrm{P}_{2} \mathrm{O}_{5}-40 \mathrm{MgO}-$ $1.5 \mathrm{AgCl}-0.5 \mathrm{Er}_{2} \mathrm{O}_{3}$; glass A: $59 \mathrm{P}_{2} \mathrm{O}_{5}-40 \mathrm{MgO}-1.0 \mathrm{AgCl}$.

The ingredient chemicals including $\mathrm{P}_{2} \mathrm{O}_{5}$ (Fluka, 95\%), $\mathrm{AgCl}$ (Chemicals $\mathrm{GmbH}, 99 \%), \mathrm{Er}_{2} \mathrm{O}_{3}$ (Sigma-Aldrich, $99.99 \%$ ) and $\mathrm{MgO}$ (Merck, 97\%) were weighed, mixed thoroughly and then put into the furnace at $400{ }^{\circ} \mathrm{C}$ for $10 \mathrm{~min}$. The temperature of the furnace was raised slowly from $400{ }^{\circ} \mathrm{C}$ to $1100^{\circ} \mathrm{C}$ at a rate of $10^{\circ} \mathrm{C} / \mathrm{min}$. The mixture was kept at $1100^{\circ} \mathrm{C}$ for $1.5 \mathrm{~h}$ in order to achieve complete melting. After the complete melting of the mixture, it was quenched on a mould of stainless steel placed inside the second furnace at $300{ }^{\circ} \mathrm{C}$ and is allowed to anneal at this temperature for $3 \mathrm{~h}$ after which it was allowed to cool slowly to the room temperature. Finally, the glass samples were cut with a size of $\approx 2 \times 2 \mathrm{~cm}$ and thickness $\approx 0.3 \mathrm{~cm}$ and polished for optical and spectroscopic measurements. The amorphous nature of the sample is confirmed by X-ray diffraction (XRD) measurements (Bruker D8 Advance diffractometer) using $\mathrm{Cu} K_{\alpha}$ radiations $(\lambda=1.54 \AA)$ at $40 \mathrm{kV}$ and $100 \mathrm{~mA}$ with $2 \theta$ ranges from 0 to $60^{\circ}$. Transmission electron microscope 
(TEM) measurements are made (TEM 2100, JEOL) with an acceleration voltage of $200 \mathrm{kV}$ to find the nucleation of silver NPs. Specimens for TEM are prepared by dispersing the powder sample in acetone using ultrasonic bath. The solution is then placed onto copper grid and then let to dry before it got ready for characterization. For the infrared (IR) measurements the glasses were powdered and mixed with $\mathrm{KBr}$ in order to obtain thin pellets. The IR spectra were obtained with Perkin-Elmer Spectrum One Fourier transform IR (FTIR) spectrometer. Shimazu UV-3101PC scanning spectrophotometer (Kyoto, Japan) is employed to measure visible and near infrared absorption spectra in the range 190-2000 nm. Perkin Elmer LS-55 luminescence spectrometer (U.K.) is used for recording emission spectra.

\section{Results and discussion}

\subsection{X-ray diffraction technique}

Figure 1 illustrates the XRD patterns confirming the amorphous nature of the host glass.

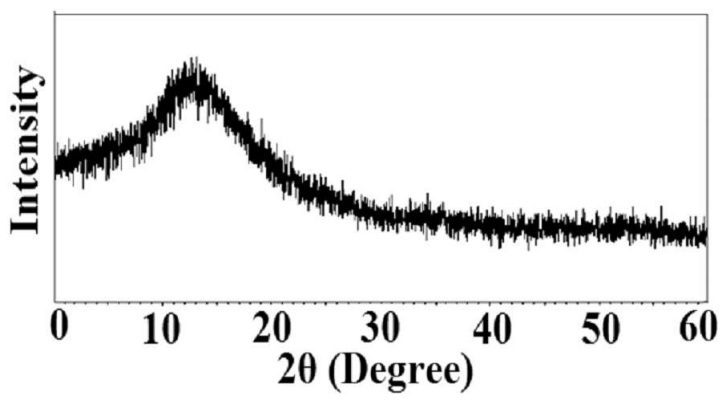

Fig. 1. XRD profile of glass E.

\subsection{Transmission electron microscopy}

TEM image clearly shows the existence of silver NPs (Fig. 2a). Figure 2b shows the high resolution TEM (HRTEM) of one single NP. The obtained lattice constant is $2.13 \AA$ which is comparable to that of bulk $\mathrm{Ag}$ $\left(d_{200}=2.05 \AA\right.$, JCPDS No. 030931). Hence the NPs observed are indeed the Ag NPs [8].

\subsection{Fourier transform infrared spectroscopy}

Figure 3 shows the IR spectra for the samples with and without silver NPs. The most intense peak is located at $823 \mathrm{~cm}^{-1}$ attributed to the symmetrical stretching vibration of $\mathrm{P}-\mathrm{O}-\mathrm{P}$ bonds. Other prominent absorption signal which originates from the $\left(\mathrm{PO}_{3}\right)^{2-}$ asymmetric vibrations can be seen around 1041, while the peak around $642 \mathrm{~cm}^{-1}$ is assigned to $\mathrm{P}-\mathrm{O}-\mathrm{P}$ bending vibrations. Peak around $688 \mathrm{~cm}^{-1}$ is attributed to $\mathrm{P}-\mathrm{O}-\mathrm{P}$ symmetric stretching vibrations, moreover the peak around $1237 \mathrm{~cm}^{-1}$ is due to $\left(\mathrm{PO}_{2}\right)^{-}$asymmetric stretching vibrations. Due to the hygroscopicity of the samples there is a
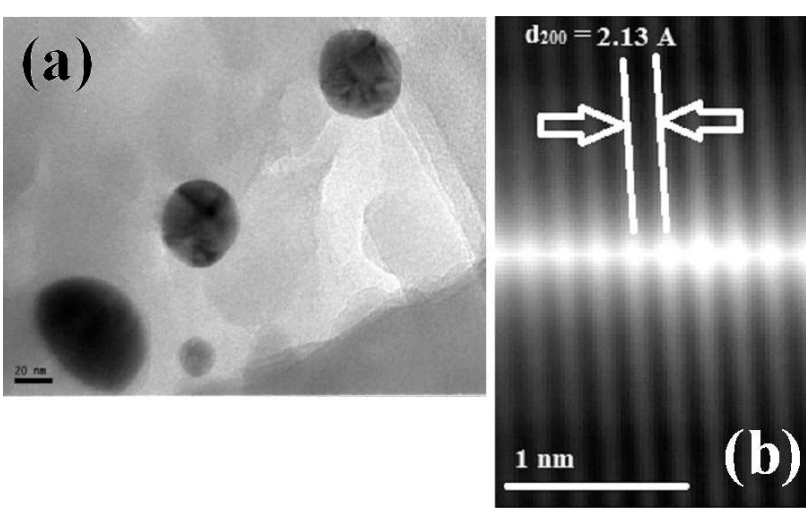

Fig. 2. (a) TEM image for sample EA, (b) HRTEM of one single NP in glass EA.

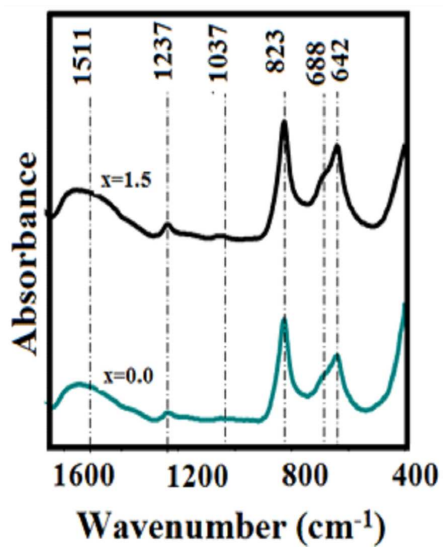

Fig. 3. IR spectra for sample E and EA.

peak around $1506 \mathrm{~cm}^{-1}$ due to free $\mathrm{H}_{2} \mathrm{O}$ molecules. Observed peaks and their assignments are shown in Table.

By looking at the IR spectra closely one can also see the slight increase in the intensity of the bands around 642, 823 and $1237 \mathrm{~cm}^{-1}$ as the silver concentration increases. From the above results we can conclude that the presence of silver NPs produces a distortion in $\mathrm{PO}_{4}$ units as well as an attenuation of the $\mathrm{P}=\mathrm{O}$ bond.

Peaks observed and their assignment.

TABLE

\begin{tabular}{c|c}
\hline \hline $\begin{array}{c}\text { Peaks observed } \\
\text { in all samples }\end{array}$ & Peak assignments $^{a}$ \\
\hline 642 & $\delta(\mathrm{P}-\mathrm{O}-\mathrm{P})$ \\
688 & $\nu_{\mathrm{s}}(\mathrm{P}-\mathrm{O}-\mathrm{P})$ \\
823 & $\nu_{\mathrm{s}}(\mathrm{P}-\mathrm{O}-\mathrm{P})$ \\
1041 & $\nu_{\text {as }}\left(\mathrm{PO}_{3}\right)^{2-}$ \\
1237 & $\nu_{\text {as }}\left(\mathrm{PO}_{2}\right)^{-}$ \\
1511 & free $\mathrm{H}_{2} \mathrm{O}$ molecules \\
\hline
\end{tabular}

Abbreviations: $\delta$ - deformation, $\nu$ - stretching, $\mathrm{s}$ - symmetric, as - asymmetric.

${ }^{a}$ Refs. [9-13]. 


\section{4. $U V$-VIS-NIR absorption spectroscopy}

The measured absorption spectra of $\mathrm{Er}^{3+}$ doped glasses in the range of 200-1600 nm shows ten absorption bands as depicted in Fig. 4 . These bands include ${ }^{4} I_{13 / 2}$, ${ }^{4} I_{11 / 2},{ }^{4} I_{9 / 2},{ }^{4} F_{9 / 2},{ }^{4} S_{3 / 2},{ }^{2} H_{11 / 2},{ }^{4} F_{7 / 2},{ }^{4} F_{5 / 2},{ }^{2} G_{9 / 2}$, ${ }^{4} G_{11 / 2}$ transitions. The spectra of all the glasses display narrow features related to the $4 f-4 f$ electronic transition of $\mathrm{Er}^{3+}$. One new erbium free sample containing $1.0 \mathrm{~mol} . \%$ of $\mathrm{AgCl}$ (glass A) is prepared and surface plasmon resonance (SPR) band is found to be located around $\approx 528 \mathrm{~nm}$. The position of SPR band also gives evidence that it overlaps with strong ${ }^{2} H_{11 / 2}$ band of $\mathrm{Er}^{3+}$ in previous sample containing both $\mathrm{Er}^{3+}$ and $\mathrm{Ag}$. The emergence of SPR band along with TEM confirms the complete reduction of silver $\left(\mathrm{Ag}^{+} \rightarrow \mathrm{Ag}^{0}\right)$, however the existence of other species of silver (ions, dimers and trimers) is likely [14-16].

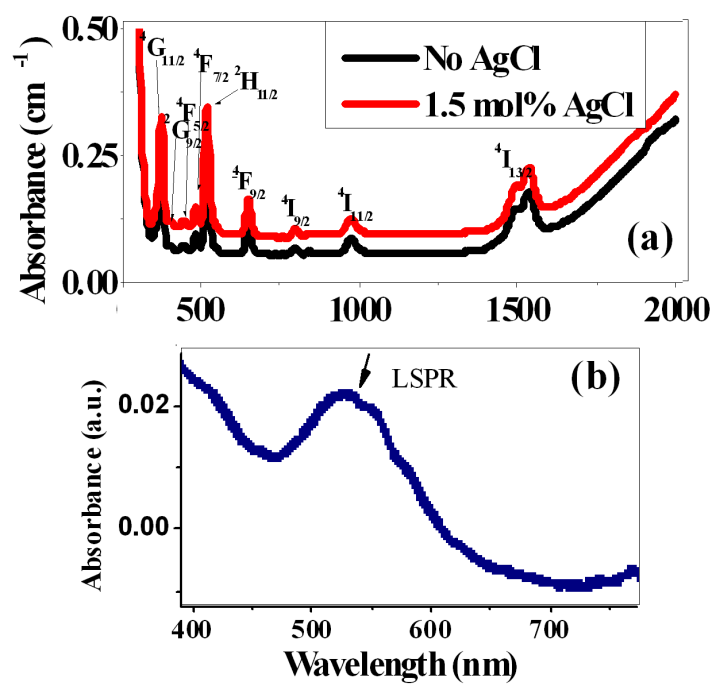

Fig. 4. (a) Absorption spectra of glass E and EA, (b) SPR position of silver NPs in glass A.

\subsection{Photoluminescence (PL) spectroscopy}

Figure 5 represents the luminescence spectra for $\mathrm{Er}^{3+}$ doped phosphate glass (a) without $\mathrm{AgCl}$, (b) with $1.5 \mathrm{~mol} . \% \mathrm{AgCl}$ under the excitation wavelength $797 \mathrm{~nm}$. The two bands observed with peaks $\approx 540 \mathrm{~nm}$ and $\approx 632 \mathrm{~nm}$ are designated to the ${ }^{4} S_{3 / 2}{ }^{4} I_{15 / 2}$ and ${ }^{4} F_{9 / 2}-{ }^{4} I_{15 / 2}$ transitions, respectively. From Fig. 5 it is evident that the UC intensity enhances with increasing the NPs concentration. This enhancement is again due to the presence of local field effect in the vicinity of the rare-earth ions [17]. Furthermore, it is found that the green emission at $540 \mathrm{~nm}$ due to $\mathrm{Er}^{3+}$ transition $\left({ }^{4} S_{3 / 2}{ }^{-}{ }^{4} I_{15 / 2}\right)$ is much influenced by the silver NPs compared to the red emission at $632 \mathrm{~nm}\left({ }^{4} F_{9 / 2}-{ }^{4} I_{15 / 2}\right)$. These enhancements are attributed due to the presence of silver NPs. Moreover, the rapid increase in the intensity of the green band as compared to the red band can be explained by considering the charge cloud effect of the plasmon band. The rapid increase of the green band compared to the far lying red bands is due to the fact that green band lies more close to the plasmon frequency band of Ag. These findings are in good qualitative agreement with other reports [18].

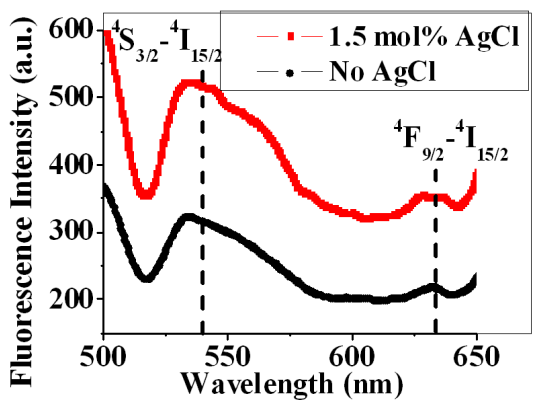

Fig. 5. Luminescence spectra of glass E and EA.

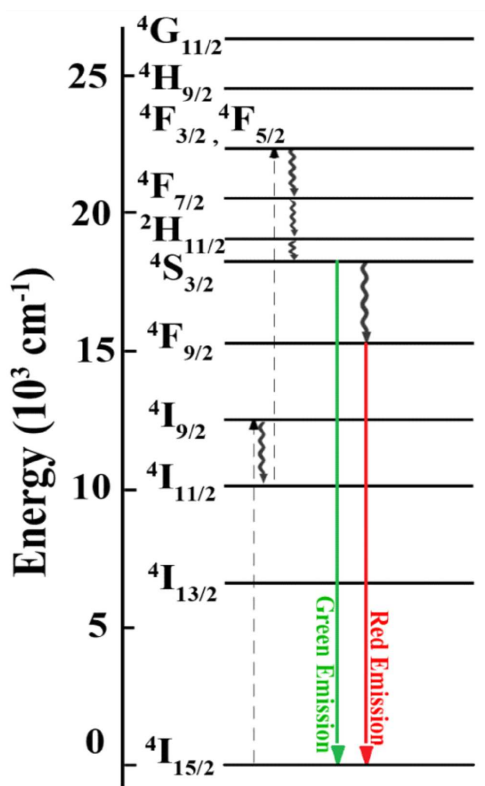

Fig. 6. Simplified $\mathrm{Er}^{3+}$ energy level scheme with indication of the transitions observed.

The excitation mechanism can be explained using the energy level scheme shown in Fig. 6. The incident photon is first absorbed by the $\mathrm{Er}^{3+}$ ion and gets transferred to the upper energy level ${ }^{4} I_{9 / 2}\left({ }^{4} I_{15 / 2} \rightarrow{ }^{4} I_{9 / 2}\right)$. The ion decays nonradiatively from level ${ }^{4} I_{9 / 2}$ to the lower excited level ${ }^{4} I_{11 / 2}$. Finally, it absorbs another photon and then gets promoted to ${ }^{4} F_{5 / 2}$ and ${ }^{4} F_{3 / 2}$ levels. The excited ions in ${ }^{4} F_{5 / 2},{ }^{4} F_{3 / 2}$ levels decay non-radiatively to ${ }^{4} S_{3 / 2}$ and from this state, decay radiatively to ${ }^{4} I_{15 / 2}$ state, and nonradiatively to the ${ }^{4} F_{9 / 2}$ state, followed by radiative decay through ${ }^{4} F_{9 / 2} \rightarrow{ }^{4} I_{15 / 2}$ transition. 


\section{Conclusion}

In summary, optical and structural investigation of $\mathrm{Er}^{3+}$ doped, silver NPs embedded phosphate glass is carried out. The XRD spectra confirm the amorphous nature of the host glass. TEM image shows the existence of silver NPs inside the glass host and from HRTEM the obtained lattice constant is $2.13 \AA$. From IR spectroscopy it is clear that the presence of silver NPs produces a distortion in $\mathrm{PO}_{4}$ units as well as an attenuation of the $\mathrm{P}=\mathrm{O}$ bond. From UV-VIS-NIR spectroscopy a strong SPR band is found to be located at $528 \mathrm{~nm}$ for an $\mathrm{Er}^{3+}$ free sample. This is clear from the current study that upconversion emission is sensitive to rare-earth doped glasses containing metallic NPs and can be enhanced by many folds in the presence of these nanoparticles. The enhancement is attributed to the local field effect of silver NPs. Our findings may contribute towards the development of solid state laser and sensors.

\section{Acknowledgments}

The authors gratefully acknowledge the financial support from RMC through research grants from MOHE/ GUP (Vote 02J22 and 06J33) and IDF UTM.J.10.01/ 13.14//128 (201009M10001) from UTM and experimental assistance from Universiti Teknologi Malaysia, Faculty of Science. R.J.A. is thankful to Prof. Dr. S. Naseem (Director CSSP, PAK) for his continuous encouragement and support throughout this project.

\section{References}

[1] L.P. Naranjo, C.B. de Araujo, O.L. Malta, P.A. Santa Cruz, L.R.P. Kassab, J. Appl. Phys. Lett. 87, 241914 (2005).

[2] Rare Earth Doped Fiber Lasers and Amplifiers, Ed. M.J. Digonnet, Dekker, New York 1993.
[3] P.N. Prasad, Nanophotonics, Wiley, New York 2004.

[4] Y. Hamanka, A. Nakamura, S. Omi, N. Del Fatti, F. Vallee, C. Flytzanis, J. Appl. Phys. Lett. 75 , 1712 (1999)

[5] T. Hayakawa, S. Selvan, M. Nogami, J. Appl. Phys. Lett. 74, 1513 (1999).

[6] M.I. Abd El-Ati, A.A. Higazy, J. Mater. Sci. 35 , 6175 (2000).

[7] T.I. Suratwala, R.A. Steele, G.D. Wilke, J.H. Campbell, K. Takeuchi, J. Non-Cryst. Solids 263-264, 213 (2000).

[8] C. Liu, J. Heo, J. Am. Chem. Soc. 93, 3349 (2010).

[9] G. Le Saout, P. Simon, F.F. Fayon, A. Blink, Y. Vaills, J. Raman Spectrosc. 33, 740 (2002).

[10] M. Hafid, T. Jermoumi, N. Niegisch, M. Mennig, Mater. Res. Bull. 36, 2375 (2001).

[11] S.T. Reis, D.L.A. Faria, J.R. Martinelli, W.M. Pontuschka, D.E. Day, C.S.M. Partiti, J. Non-Cryst. Solids 304, 188 (2002).

[12] D. Ilieva, B. Jivov, G. Bogachev, C. Petkov, I. Penkov, Y. Dimitriev, J. Non-Cryst. Solids. 283, 195 (2001).

[13] C. Dayanand, G. Bhikshamaiah, V. Jaya Tyagaraju, M. Salagram, A.S.R. Krishna Murthy, J. Mater. Sci. 31, 1945 (1996).

[14] M.R. Dousti, M.R. Sahar, R.J. Amjad, S.K. Ghoshal, A. Khorramnazari, A. Dordizadeh Basirabad, A. Samavati, Eur. Phys. J. D 66, 237 (2012).

[15] A. Chiasera, M. Ferrari, M. Mattarelli, M. Montagna, S. Pelli, H. Portales, J. Zheng, G.C. Righini, Opt. Mater. 27, 1743 (2005).

[16] G. Speranza, L. Minati, A. Chiasera, M. Ferrari, G.C. Righini, G. Ischia, J. Phys. Chem. C 113, 4445 (2009).

[17] S.K. Singh, N.K. Giri, D.K. Rai, S.B. Rai, J. Solid State Sci. 12, 1480 (2010).

[18] T. Som, B. Karmakar, Plasmonics 5, 149 (2010). 